Military Technical College Kobry El-Kobbah, Cairo, Egypt

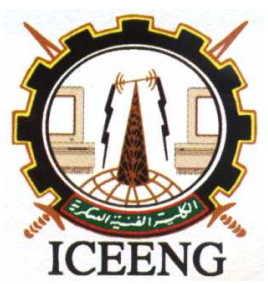

ICEENG

\author{
$6^{\text {th }}$ International Conference \\ on Electrical Engineering \\ ICEENG 2008
}

\title{
LIGHTNING PROTECTION USING FRANKLIN RODS
}

By

\author{
Mazen Abdel-Salam *
}

\section{$\underline{\text { Abstract: }}$}

Under normal conditions, the electric field at ground level remains at a value of several hundreds of volts per meter. Under thunderstorm conditions, the electric field could reach as high as several thousands of volts per meter. The increase in the electric field is attributed to the charge separation in the cloud.

The lightning stroke is initiated by the formation of a negative downward leader at the storm cloud, which advances in steps toward the ground. This results in enhancement of the field at the tip of the Franklin rod, with a subsequent formation of corona streamer discharge, which may turn into a positive upward leader. As the upward leader progresses, it influences the path of the downward leader propagating toward the ground. Both downward and upward leaders converge until interception occurs, where a conducting path between the cloud and ground is completed to convey the lightning current to ground.

For a given rod, the upward-directed streamers start from the rod at downward leader heights that depend on the lightning current. The higher this current, the higher is the location where the upward- and downward-directed leaders meet each other and the more is the protection area around the rod. Energizing the rod influences the onset condition of upward streamers and the radius of protection. This improves the protection efficiency of the rod in capturing the downward leaders

* Fellow, IEEE(USA), IEE, Fellow(UK), Fellow, IOP(UK), Fellow AvH(Germany), EE Department, Assiut University, Assiut, Egypt 